\title{
A review of technical progression in the robot-assisted radical prostatectomy
}

\author{
Eric Y. Cho, Kevin K. Yang, Ziho Lee, Daniel D. Eun \\ Department of Urology, Temple University Hospital, Philadelphia, PA, USA \\ Contributions: (I) Conception and design: EY Cho; (II) Administrative support: DD Eun; (III) Provision of study materials or patients: KK Yang; (IV) \\ Collection and assembly of data: EY Cho, KK Yang; (V) Data analysis and interpretation: EY Cho, KK Yang, Z Lee; (VI) Manuscript writing: All \\ authors; (VII) Final approval of manuscript: All authors. \\ Correspondence to: Eric Cho. 3509 Broad St., Philadelphia, PA 19140, USA. Email: eric.cho@tuhs.temple.edu.
}

\begin{abstract}
Since the advent of the robotic surgery, its implementation in urology has been both wide and rapid. Particularly in extirpative surgery for prostate cancer, techniques in robotic-assisted radical prostatectomy have-and continue to-evolve to maximize functional and oncologic outcomes. In this review, we briefly present a historical perspective of the evolution of various robotic techniques, allowing us to contextualize contemporary robotic approaches to radical prostatectomy.
\end{abstract}

Keywords: Techniques; robotic prostatectomy; advancements

Submitted Aug 08, 2019. Accepted for publication Feb 17, 2020.

doi: $10.21037 /$ tau.2020.03.17

View this article at: http://dx.doi.org/10.21037/tau.2020.03.17

\section{Introduction}

The robot-assisted radical prostatectomy (RARP) was first reported by Binder and Kramer in 2001 (1). Since its initial descriptions, the technique was rapidly adopted and has become the most commonly offered surgical treatment for prostate cancer (2). As the robotic approach became more popular and various techniques evolved, greater emphasis was made to improve functional urinary and sexual outcomes while maintaining oncologic control. Greater understanding of the periprostatic anatomy combined with developing surgical techniques with the robotic platform have allowed the previously "cookie cutter" radical prostatectomy to become a surgery that is tailored to the specific needs of the patient to maximize outcomes (3). In this review, we aim to highlight various techniques in the robotic era that have been developed to optimize functional outcomes in the radical prostatectomy patient.

\section{Anterior versus posterior approach}

The earliest RARP technique was naturally derived directly from the laparoscopic approach, which was popularized in the late 1990's and early 2000's as the Montsouris Technique $(4,5)$. This transperitoneal approach, which involved early posterior dissection and release of the vas deferens and seminal vesicles prior to opening the space of Retzius, was eventually coined as the "posterior approach", given the stark contrast to the open technique as described by Dr. Walsh (6). After gaining early experience with a robotic Montsouris approach, Dr. Menon's team in Detroit described a more anatomical approach that was more closely derived from the open retropubic experience and was later formalized as the Vattikuti Institute Prostatectomy $(7,8)$. This minimally invasive departure from the "posterior" Montsouris Technique involved opening the space of Retzius as the first step, much like the open approach, and was eventually coined as the "anterior approach". Although neither of these approaches were associated with superior outcomes, this early divergence in two distinctly different techniques formed two schools of thought regarding preference of technique.

\section{Bladder neck preservation (BNP)}

BNP aims at improving urinary functional outcomes 
in post-prostatectomy patients but have remained controversial as it is weighed against the risk of increased positive margin rates. Two meta-analyses reported conflicting findings of BNP with one study in 2013 demonstrating good continence and equivalent oncologic outcomes (9), and another in 2017 demonstrating possible increases in base-positive margins (10). The 2013 analysis by Smolski et al. included 31 original studies and two review articles involving BNP verses bladder neck reconstruction in open, laparoscopic and robotic radical prostatectomies. Overall, BNP was found to have no effect on positive surgical margins and BNP was associated with improved overall continence and improved early continence. The 2017 analysis by Bellangino et al. included 15 studies which reported overall and site-specific positive surgical margin rates following BNP prostatectomy and included open (8 studies), laparoscopic (3 studies), robotic (3 studies) and both open and robotic (1 study) approaches. Overall, the data suggested that BNP may be associated with an increase of base-positive margins. However, in regards to both analyses, deriving a conclusion without delving into individual patient consideration would be too much of an oversimplification, and BNP remains an oncologically investigated technique.

Deliveliotis (2002) first reported cases utilizing BNP with improved early return to continence in open radical prostatectomy patients (11). One of the major challenges of a BNP in RARP was that the surgeon could not rely on palpation of the foley catheter and balloon to localize the bladder neck and urethra. The standard technique of bladder neck dissection in RARP was imprecise and often resulted in a wide bladder neck that required reconstruction (typically by means of a tennis racquet repair). Freire et al. (2009) was the first to describe a technique of BNP in RARP which utilized the fourth robotic arm to provide anterocephalad tension on the bladder. The traction allowed for delineation of a detrusor "ridge" where the bladder tissue ends and prostatic tissue begins and served as an anatomic landmark for the dissection. After the bladder neck was dissected 270 degrees anteriorly, the foley catheter was then passed through the opening and tension held on the catheter by the assistant using a laparoscopic grasper. In Freire's description, the functional outcomes of patients undergoing BNP ( $\mathrm{n}=348)$ were compared to those with the standard technique bladder neck dissection $(n=271)$. They observed $94.1 \%$ of the BNP group reported improved urinary function scores at 24 months versus 86.8 in the standard technique group, and $65.6 \%$ of the BNP group reported complete continence (defined as zero pads per day) at 4 months vs. $26.5 \%$ of the standard technique group (12). Hashimoto et al. (2018) performed a retrospective multivariate analysis on 199 RARP patients comparing the anterior BNP technique with a lateral BNP technique, which was first reported by Jeong et al. and known as ultradissection of the lateral bladder neck. The results of this analysis found the lateral BNP technique to be independently associated with urinary continence recovery $(\mathrm{P}<0.01)$ with good oncologic outcomes $(13,14)$.

\section{Rhabdosphincter reconstruction:}

In 2001, Rocco et al. presented a modification of the Walsh $\mathrm{RP}$ in which they aimed to improve urinary continence outcomes in prostatectomy patients by fixing the posterior bladder wall to the Denonvilliers' fascia at the posterior semicircumference of the sphincter prior to initiating the vesicourethral anastomosis (15). This became colloquially known as the "Rocco stitch". The anatomical rational that drove the technique was the hypothesis that post-operative urinary incontinence was due to sphincter insufficiency driven by the natural caudal retraction of the urethral sphincter complex which shortened the urethral sphincter length. When compared to the traditional RP patients, they found that post-operatively patients experienced a shorter time of return to continence. Coughlin et al. was the first to report the application of rhabdosphincter reconstruction in the RARP in 2008 with similar early return to continence (16). It is important to note that early return to continence has not been consistently validated in future studies. In 2008, Menon conducted a randomized control trial in 116 patients in which 57 patients underwent RARP without rhabdosphincter reconstruction and 59 patients with, and found no difference in early return to continence rates between the two groups (17).

\section{Apical dissection}

Due to the difficulty delineating prostatic tissue from the urethral sphincter complex, the prostatic apex was traditionally regarded as the anatomic location in which positive surgical margins were the most common. Therefore, a robust prostatic apical dissection was developed and has evolved since the days of open radical prostatectomy with the goal of reducing positive surgical margin rates (18). Menon (2004) was the first to describe apical dissection in RARP, and since that time there has 
been progression of various apical dissection techniques (19). While initially the priority was to avoid positive surgical margins, the apical dissection has proven utility in the improvement of functional urinary outcomes as well.

Tewari et al. (2010) described the retro-apical technique which was performed with concomitant urethral transection in 209 patients. They hypothesized that a meticulous dissection of the prostatic apex would obviate the demarcation of the urethral-prostatic junction to allow for precise transection of the urethra whilst preserving urethral length. This differed from the traditional practice in which bulky urethral tissue was often divided sharply without delineating the urethral-prostatic junction. Tewari's apical dissection technique was retrospectively reviewed against 1665 previous patients with conventional dissection and resulted in a significantly lower rate of positive margins at $1.4 \%$ versus $4.4 \%(\mathrm{P}=0.04)$ despite a higher percentage of aggressive cancers in the retro-apical cohort (20). Although preserving urethral length has been shown to improve continence and time to return to continence, this outcome was not analyzed in the study (21).

In 2018, Bianchi et al. proposed a novel "collar" technique, which aimed to preserve maximal length of the urethra in order to analyze effects on rates of positive surgical margins (primary outcome) as well as urinary continence (secondary outcome). The technique involved incising the superficial urethral sphincter complex slightly distal to the prostatic apex to expose the smooth muscle and transecting the urethra at the level of the smooth muscle (lissosphincter) proximally towards the apex to create a "collar". The results reported lower rates of positive surgical margins in the collar group (5.6\%) compared to the control group of a standard apical dissection (9.9\%). However, despite the extended urethral length achieved by this technique, there was similar continence recovery in both groups (22).

\section{Neurovascular bundle preservation}

Nerve sparing (NS) technique was first described by Walsh in his seminal paper in 1981, which delineated the anatomy of the pelvic plexus and how avoiding injury to the neurovascular bundle could aim to preserve erectile function in post-prostatectomy men (23). Menon et al. (2003) was the first to describe a "standard" NS approach robotically, in which an anatomical triangular tunnel was described (consisting of the periprostatic fascia splitting and fusing with Denonvillier's fascia) and surgically preserved in order to avoid damaging the posterolateral neurovascular bundle with similar goals (8). However, this paper was written to describe the technical feasibility of the then-novel RARP rather than reporting outcomes and no data regarding erectile function preservation was presented at that time. Since then, there have been numerous descriptions of different NS techniques which will be generally accounted for below. With regards to urinary continence, there have been discussion regarding whether NS technique attributes to improved outcomes with the suggestion that the meticulous dissection that results from NS may be what accounts for such findings rather than the act of preserving the neurovascular bundle preservation itself $(24,25)$. To best understand the described techniques, we suggest reading the individual references and studying the associated videos that may be available.

\section{Veil of Aphrodite}

Based on nerve staining anatomical studies which showed presence of nerves lateral and anterior to the prostatic capsule, Menon et al. (2004), further expounded on NS techniques when he described a method of micro-dissecting the lateral prostatic fascia from the capsule, leaving a lateral curtain of tissue along with athermal preservation of the neurovascular bundle; this was coined the "veil of Aphrodite" (26). By 2012, this lateral dissection plane was described to extend anteriorly and medially to include the dorsal venous complex structures, creating the so-called "super veil"reserved for those with relative lower risk disease and who desired maximal preservation of potency (27). Although, not delineated in this paper, but a prior study by the same group showed that in men with a preoperative Sexual Health Inventory for Men (SHIM) score of $>17,42 \%$ of these patients had postoperative SHIM scores between 18-25, $19 \%$ with scores $12-17,14 \%$ with scores $8-11$ and $25 \%$ with scores $<7$ demonstrating favorable sexual outcomes at 18 month follow-up (28). However, these studies did not demonstrate a significant overall improvement in SHIM scores and ability to achieve sexual penetration when comparing "standard veil" versus "super veil" groups.

\section{Interfascial and intrafascial dissection}

Owing to the visual magnification afforded by laparoscopic techniques, Martínez-Piñeiro et al. (2006) first characterized an interfascial plane-an avascular plane between the prostatic and Denonvillier's fascia. Likewise, an intrafascial 
plane immediately under the prostatic fascia was also described (29). While dissection of the interfascial plane is more commonly adopted, an athermal intrafascial robotic (AIR) technique was developed with hopes of maximizing NS capabilities. Potdevin et al. performed a retrospective review comparing two cohorts of interfascial $(n=77)$ and intrafascial $(\mathrm{n}=70)$ techniques (30). The result was a shorter time to continence and potency as well as an absolute increase in potency in the AIR technique group. However, it was associated with higher rates of positive surgical margins indicating the importance of patient selection for this approach.

\section{Athermal dissection}

Gill (2007) initially presented an athermal technique for the NS dissection in which bulldog clamps were used over the prostatic pedicles while the prostatic fascia was dissected and hemostasis achieved with suture ligation. In that study, 76 patients were followed for at least 1 year showing that patients undergoing athermal dissection $(\mathrm{n}=64)$ had a 1 -year successful intercourse rate of $70 \%$ versus the thermalenergy based technique cohort $(\mathrm{n}=22)$ of $36 \%(\mathrm{P}=0.04)(31)$. It has since been accepted that cautery in the vicinity of the neurovascular bundle should be avoided when possible to prevent collateral damage to surrounding nerves.

\section{Neural hammock preservation}

In 2011, Tewari et al. redefined the prostatic neurovascular network more as a hammock-like distribution of nerves underlying the prostate as opposed to the traditional view of a cord-like "bundle". A novel technique of NS was described which included athermal, traction-free dissection of the neurovascular hammock. This technique was riskstratified in 2,317 patients (with degree of NS depending on clinical grade and stage of disease). The analysis indicated statistically significant improvement of potency and return to baseline SHIM with more aggressive NS techniques (32).

\section{Athermal early retrograde nerve release}

In 2009, Coughlin described a robotic NS technique of an athermal release of the neurovascular bundle in a retrograde fashion from the prostatic apex to the base. Prior to this description, this approach of NS was limited to the open radical prostatectomy (33). Couglin's technique emphasized an early neurovascular bundle release prior to ligation of the prostatic pedicles with the aim of early NS to mitigate injury to the neurovascular bundles that was commonly experienced during prostatic pedicle ligation. By integrating the benefits of robotic surgery with open surgical principles, this "hybrid technique" aimed for maximal neurovascular preservation and functional outcomes. This technique was validated and replicated in a review of 12,000 prostatectomies. In this review, overall positive surgical margins were found to be $14-20.8 \%$ for pT2-pT3 stage diseases; 1 -year continence rates were $>90 \%$; and potency rates at 3, 6, 12 and 18 months were $38.8 \%, 65.4 \%, 73.9 \%$ and $95 \%$ respectively (34). The authors noted that early return to continence was not appreciated in their analysis.

\section{Retzius-sparing approach}

Bocciardi's group (2010) was the first to describe a case series of 5 patients that underwent a Retzius-sparing approach for RARP, in which an intrafascial prostatectomy was performed via access through the Douglas space. This approach maintains the bladder in its orthotopic configuration within the space of Retzius unperturbed, hence preserving anterior bladder support, dorsal venous complex structures and posterior-lateral structures involved with urinary continence and possibly potency. This posterior space is then developed laterally and anteriorly, while staying within the intrafascial plane, theoretically resulting in a superior neural and vascular preserving dissection (35). Bocciardi et al. later followed with a series of 200 patients with a minimum of 1 -year follow-up, the approach was found to be oncologically and technically feasible (36). This approach has been replicated and validated to report improved short term continence return, urinary function and subjective symptom reports $(37,38)$. The limitations of this approach involve the technical complexity of such meticulous dissection and its associated steep learning curve involved to achieve optimal outcomes.

\section{Partial prostatectomy}

The robot-assisted partial prostatectomy (RAPP) was developed as a surgical version of energy-based prostatic ablation for localized disease where carcinoma arose in the anterior and medial transition zones near the external sphincter and neurovascular bundles. Such anterior prostate cancers (APC) are being discovered with the recent adaption of magnetic resonance imaging (MRI) and 
subsequent targeted prostate biopsies, and account for up to $19 \%$ of new prostate cancer diagnoses (39). Postoperatively, oncologic outcomes can be followed by prostate-specific antigen (PSA) values and recurrence can be treated with salvage RP or ablative techniques when indicated. The earliest case series of RAPP was reported by Villers (2017) in highly selective population of 17 patients with favorable intermediate-risk prostate cancer and reported an $86 \%$ 2-year recurrence-free survival rate with $100 \%$ continence and $83 \%$ potency at 3 months (40). Given the stringent selective inclusion criteria for this patient population, it remains an investigated technique.

\section{Conclusions}

The RARP has evolved tremendously since its conception in earliest reports. Its wide adaption within the urologic community has resulted in numerous novel approaches with the aims of improving patient outcomes while maintaining oncological success. Continued refinement and development of these techniques are still on the horizon. It has become apparent that various technical modifications are optimal for select patient populations as many studies risk-stratify cohorts by sexual function, urinary symptomatology and pre-operative oncologic grade and staging. Some approaches are intuitive such as limited NS in patients with limited preoperative sexual function. However, as refinements to various techniques continue to evolve while our understanding of the complex periprostatic anatomy expands, technical mastery of this operation continues to be elusive and increasingly difficult for surgeons to learn. Even still, novel tools such as improved imaging modalities and newer generations of robotic platforms are becoming integrated into the standard of care for prostate surgery, and the ceiling to success of surgical treatment for prostate cancer-if it exists to begin with - continues to rise. What will not change is that improved outcomes for radical prostatectomy has and always will be attainable to the surgeon who focuses on increasing their experience, honing their techniques and maintaining a diligence for excellence.

\section{Acknowledgments}

Funding: None.

\section{Footnote}

Provenance and Peer Review: This article was commissioned by the Guest Editors (Marc C. Smaldone and Jeffrey J. Tomaszewski) for the series "Controversies in Minimally Invasive Urologic Oncology" published in Translational Andrology and Urology. The article has undergone external peer review.

Conflicts of Interest: All authors have completed the ICMJE uniform disclosure form (available at http://dx.doi. org/10.21037/tau.2020.03.17). The series "Controversies in Minimally Invasive Urologic Oncology” was commissioned by the editorial office without any funding or sponsorship. DDE: (I) Intuitive: consultant, proctor, speaker, meeting activity participant; (II) Johnson \& Johnson: consultant; (III) Hitachi: trainee support (not personnel); (IV) Melzi Corp: founder/owner/shareholder. The authors have no other conflicts of interest to declare.

Ethical Statement: The authors are accountable for all aspects of the work in ensuring that questions related to the accuracy or integrity of any part of the work are appropriately investigated and resolved.

Open Access Statement: This is an Open Access article distributed in accordance with the Creative Commons Attribution-NonCommercial-NoDerivs 4.0 International License (CC BY-NC-ND 4.0), which permits the noncommercial replication and distribution of the article with the strict proviso that no changes or edits are made and the original work is properly cited (including links to both the formal publication through the relevant DOI and the license). See: https://creativecommons.org/licenses/by-nc-nd/4.0/.

\section{References}

1. Binder J, Kramer W. Robotically-assisted laparoscopic radical prostatectomy. BJU Int 2001;87:408-10.

2. Trinh QD, Sammon J, Sun M, et al. Perioperative outcomes of robot-assisted radical prostatectomy compared with open radical prostatectomy: results from the nationwide inpatient sample. Eur Urol 2012;61:679-85.

3. Walz J, Epstein JI, Ganzer R, et al. A Critical Analysis of the Current Knowledge of Surgical Anatomy of the Prostate Related to Optimisation of Cancer Control and Preservation of Continence and Erection in Candidates for Radical Prostatectomy: An Update. Eur Urol 2016;70:301-11.

4. Guillonneau B, Vallancien G. Laparoscopic radical prostatectomy: the Montsouris technique. J Urol 2000;163:1643-9. 
5. Pasticier G, Rietbergen JB, Guillonneau B, et al. Robotically assisted laparoscopic radical prostatectomy: feasibility study in men. Eur Urol 2001;40:70-4.

6. Reiner WG, Walsh PC. An anatomical approach to the surgical management of the dorsal vein and Santorini's plexus during radical retropubic surgery. J Urol 1979;121:198-200.

7. Tewari A, Peabody J, Sarle R, et al. Technique of da Vinci robot-assisted anatomic radical prostatectomy. Urology 2002;60:569-72.

8. Menon M, Tewari A, Peabody J, et al. Vattikuti Institute prostatectomy: technique. J Urol 2003;169:2289-92.

9. Smolski M, Esler RC, Turo R, et al. Bladder neck sparing in radical prostatectomy. Indian J Urol 2013;29:338-44.

10. Bellangino M, Verrill C, Leslie T, et al. Systematic Review of Studies Reporting Positive Surgical Margins After Bladder Neck Sparing Radical Prostatectomy. Curr Urol Rep 2017;18:99.

11. Deliveliotis C, Protogerou V, Alargof E, et al. Radical prostatectomy: bladder neck preservation and puboprostatic ligament sparing--effects on continence and positive margins. Urology 2002;60:855-8.

12. Freire MP, Weinberg AC, Lei Y, et al. Anatomic bladder neck preservation during robotic-assisted laparoscopic radical prostatectomy: description of technique and outcomes. Eur Urol 2009;56:972-80.

13. Jeong W, Araki M, Park SY, et al. Robot-assisted laparoscopic radical prostatectomy in the Asian population: modified port configuration and ultradissection. Int J Urol 2010;17:297-300.

14. Hashimoto T, Yoshioka K, Gondo T, et al. The Impact of Lateral Bladder Neck Preservation on Urinary Continence Recovery After Robot-Assisted Radical Prostatectomy. J Endourol 2018;32:40-5.

15. Rocco F, Gadda F, Acquati P, et al. Personal research: reconstruction of the urethral striated sphincter. Arch Ital Urol Androl 2001;73:127-37.

16. Coughlin G, Dangle PP, Patil NN, et al. Surgery Illustrated--focus on details. Modified posterior reconstruction of the rhabdosphincter: application to robotic-assisted laparoscopic prostatectomy. BJU Int 2008;102:1482-5.

17. Menon M, Muhletaler F, Campos M, et al. Assessment of early continence after reconstruction of the periprostatic tissues in patients undergoing computer assisted (robotic) prostatectomy: results of a 2 group parallel randomized controlled trial. J Urol 2008;180:1018-23.

18. Gillitzer R, Thuroff JW. Technical advances in radical retropubic prostatectomy techniques for avoiding complications. Part II: vesico-urethral anastomosis and nerve-sparing prostatectomy. BJU Int 2003;92:178-84.

19. Menon M, Hemal AK, Tewari A, et al. The technique of apical dissection of the prostate and urethrovesical anastomosis in robotic radical prostatectomy. BJU Int 2004;93:715-9.

20. Tewari AK, Srivastava A, Mudaliar K, et al. Anatomical retro-apical technique of synchronous (posterior and anterior) urethral transection: a novel approach for ameliorating apical margin positivity during robotic radical prostatectomy. BJU Int 2010;106:1364-73.

21. Borin JF, Skarecky DW, Narula N, et al. Impact of urethral stump length on continence and positive surgical margins in robot-assisted laparoscopic prostatectomy. Urology 2007;70:173-7.

22. Bianchi L, Turri FM, Larcher A, et al. A Novel Approach for Apical Dissection During Robot-assisted Radical Prostatectomy: The "Collar" Technique. Eur Urol Focus 2018;4:677-85.

23. Walsh PC, Lepor H, Eggleston JC. Radical prostatectomy with preservation of sexual function: anatomical and pathological considerations. Prostate 1983;4:473-85.

24. Hamilton ZA, Kane CJ. Nerve-sparing Technique During Radical Prostatectomy and its Effect on Urinary Continence. Eur Urol 2016;69:590-1.

25. Michl U, Tennstedt P, Feldmeier L, et al. Nervesparing Surgery Technique, Not the Preservation of the Neurovascular Bundles, Leads to Improved Long-term Continence Rates After Radical Prostatectomy. Eur Urol 2016;69:584-9.

26. Menon M, Tewari A, Peabody JO, et al. Vattikuti Institute prostatectomy, a technique of robotic radical prostatectomy for management of localized carcinoma of the prostate: experience of over 1100 cases. Urol Clin North Am 2004;31:701-17.

27. Ghani KR, Trinh QD, Menon M. Vattikuti Institute Prostatectomy-Technique in 2012. J Endourol 2012;26:1558-65.

28. Menon M, Shrivastava A, Bhandari M, et al. Vattikuti Institute prostatectomy: technical modifications in 2009. Eur Urol 2009;56:89-96.

29. Martínez-Piñeiro L, Cansino JR, Sanchez C, et al. Laparoscopic Radical Prostatectomy. Differences Between the Interfascial and Intra-fascial Technique. Eur Urol 2006;5:331.

30. Potdevin L, Ercolani M, Jeong J, et al. Functional and oncologic outcomes comparing interfascial and intrafascial 
nerve sparing in robot-assisted laparoscopic radical prostatectomies. J Endourol 2009;23:1479-84.

31. Gill IS, Ukimura O. Thermal energy-free laparoscopic nerve-sparing radical prostatectomy: one-year potency outcomes. Urology 2007;70:309-14.

32. Tewari AK, Srivastava A, Huang MW, et al. Anatomical grades of nerve sparing: a risk-stratified approach to neural-hammock sparing during robot-assisted radical prostatectomy (RARP). BJU Int 2011;108:984-92.

33. Coughlin G, Dangle PP, Palmer KJ, et al. Athermal early retrograde release of the neurovascular bundle during nerve-sparing robotic-assisted laparoscopic radical prostatectomy. J Robot Surg 2009;3:13-17.

34. Kang SG, Shim JS, Onol F, et al. Lessons learned from 12,000 robotic radical prostatectomies: Is the journey as important as the outcome? Investig Clin Urol 2020;61:1-10.

35. Galfano A, Ascione A, Grimaldi S, et al. A new anatomic approach for robot-assisted laparoscopic prostatectomy: a feasibility study for completely intrafascial surgery. Eur Urol 2010;58:457-61.

36. Galfano A, Di Trapani D, Sozzi F, et al. Beyond the

Cite this article as: Cho EY, Yang KK, Lee Z, Eun DD. A review of technical progression in the robot-assisted radical prostatectomy. Transl Androl Urol 2021;10(5):2171-2177. doi: $10.21037 /$ tau.2020.03.17 learning curve of the Retzius-sparing approach for robotassisted laparoscopic radical prostatectomy: oncologic and functional results of the first 200 patients with $>/=1$ year of follow-up. Eur Urol 2013;64:974-80.

37. Dalela D, Jeong W, Prasad MA, et al. A Pragmatic Randomized Controlled Trial Examining the Impact of the Retzius-sparing Approach on Early Urinary Continence Recovery After Robot-assisted Radical Prostatectomy. Eur Urol 2017;72:677-85.

38. Menon M, Dalela D, Jamil M, Diaz M, et al. Functional Recovery, Oncologic Outcomes and Postoperative Complications after Robot-Assisted Radical Prostatectomy: An Evidence-Based Analysis Comparing the Retzius Sparing and Standard Approaches. J Urol 2018;199:1210-7.

39. Ouzzane A, Puech P, Lemaitre L, et al. Combined multiparametric MRI and targeted biopsies improve anterior prostate cancer detection, staging, and grading. Urology 2011;78:1356-62.

40. Villers A, Puech P, Flamand V, et al. Partial Prostatectomy for Anterior Cancer: Short-term Oncologic and Functional Outcomes. Eur Urol 2017;72:333-42. 